\title{
An Exploration of Temperature Metrics for Further Developing the Heat-Health Weather Warning System in Hong Kong
}

\author{
Cho Kwong Charlie Lam, Margaret Loughnan, and Nigel Tapper \\ School of Geography and Environmental Science, Monash University, Building 11, Melbourne, VIC 3800, Australia \\ Correspondence should be addressed to Cho Kwong Charlie Lam; cho.lam@monash.edu
}

Received 15 September 2012; Accepted 2 October 2012

Academic Editors: C. Borrego and G. A. Gerosa

Copyright (C) 2013 Cho Kwong Charlie Lam et al. This is an open access article distributed under the Creative Commons Attribution License, which permits unrestricted use, distribution, and reproduction in any medium, provided the original work is properly cited.

\begin{abstract}
Background. The current weather warning system aims to reduce mortality from heat and cold stress but still has room to be improved in terms of incorporating other temperature metrics. The aim of this study is to determine how extreme temperature affects mortality in Hong Kong. Methods. An ecological study was used; daily weather data were subdivided into seven temperature metrics. Daily detrended mortality data were stratified by disease groups and analysed using seven different metrics for temperature. The temperature metrics were then compared. Results. A diurnal temperature range (DTR) of $\geq 8^{\circ} \mathrm{C}$ leading to an increase in median mortality of up to $16 \%$ and a mean temperature change between neighbouring days of $\geq 4^{\circ} \mathrm{C}$ leading to an increase in median mortality of up to $6 \%$ were the critical thresholds for excess mortality in Hong Kong. Conclusions. This study reveals that mean net effective temperature, DTR, and temperature change between neighbouring days are effective to predict excess mortality in Hong Kong.
\end{abstract}

\section{Background}

There has been a growing interest in the impact of extreme heat and cold events on health globally. In subtropical Asia, this issue has been investigated in countries including Japan, China, and South Korea. Most heat-related mortality research in Hong Kong has been conducted in the last decade [1-5]. A summary of previous findings in Hong Kong is outlined in Table 1. A U- or J-shaped relationship is observed between temperature and mortality [5]. This is consistent with extant studies [6-8]. This paper will explore seven temperature metrics in relation to mortality in Hong Kong. In particular, the effects on mortality of diurnal temperature range (DTR) and temperature change between neighbouring days are not well understood in the Hong Kong literature. Understanding these effects will enhance the current Hong Kong heat-health weather warning system. Diurnal temperature range (DTR) is the difference between the highest and lowest temperature within a single day [9]. DTR is shown to influence heatrelated mortality in Hong Kong [10]. DTR has been decreasing from about $5.5^{\circ} \mathrm{C}$ in 1947 to about $4^{\circ} \mathrm{C}$ in 2002 [11]. Traditionally, a large DTR relieves heat stress: it assumes a cool night happens after a hot day. This effect is believed to be important in Melbourne, Australia [12]. Conversely, a large DTR might increase mortality during hot days, particularly with cardiovascular diseases [9] and strokes [13]. A large DTR might also increase blood pressure in the elderly leading to cardiovascular disease [10].

The Hong Kong Observatory (HKO) has issued very hot and cold weather warnings since 2000; these warnings are derived from a weather stress index (WSI) [14]. In Hong Kong, WSI is calculated from net effective temperature (NET), which incorporates ambient temperature, relative humidity, and wind speed [14]. It is assumed that Hong Kong people generally adapt better to hot weather than cold weather. Indeed, cold-related mortality is higher than heat-related mortality in Hong Kong [2, 14]. In addition, $\mathrm{Li}$ and Chan [14] observed that there is a skewed Ushaped relationship between WSI and mortality, in which the mortality is greater in winter months (November to March) than summer months (May to September).

The aim of this research is to further determine the impact of extreme temperatures on mortality in Hong Kong. Specifically, it examines how different temperature metrics 


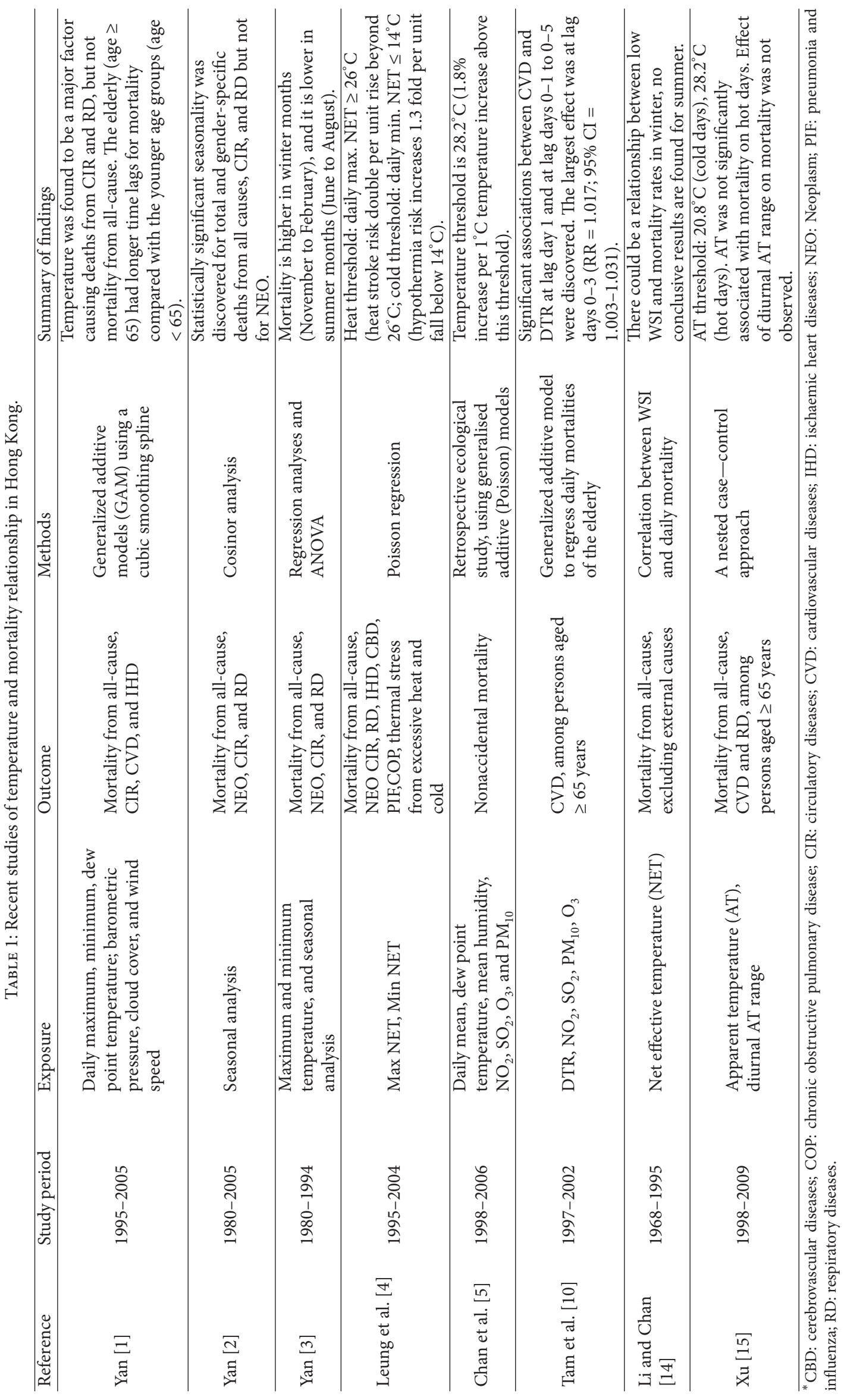


TABLE 2: Comparison between ICD-9 and ICD-10.

\begin{tabular}{lcc}
\hline & ICD-9 & ICD-10 \\
\hline All-cause & $001-999$ & A00-T98 \\
Non-accidental & $001-799$ & A00-R99 \\
Respiratory diseases (RD) & $460-519$ & J00-J99 \\
Cardiovascular diseases (CVD) & $390-459$ & I00-I99 \\
\hline
\end{tabular}

affect mortality, and which temperature metrics are better predictors of mortality in Hong Kong. Hong Kong is a densely populated subtropical city which provides a good representation of the situation of other South East Asia cities. Since relatively few studies on the effects of heat or cold stress have been conducted in Hong Kong, this paper will serve to increase the understanding of the relationship between heat/cold and population health in a subtropical urban environment.

\section{Methods}

2.1. Mortality Data. The study uses an ecological time series approach to determine the climate variables that affect mortality in Hong Kong from 1999 to 2009. The study uses deidentified mortality statistics from the Hong Kong Census and Statistics Department for analysis. Mortality data were purchased from the Census and Statistics Department in Hong Kong (time-series). The data requested were annual known death micro-data sets from 1999 to 2009. Ethics exemption was obtained from the Monash University Human Research Ethics Committee (MUHREC). The data were partitioned into all-cause mortality, respiratory, and cardiovascular mortality according to the International Classification of Diseases (ICD) 9 and 10 (Table 2). RD refers to respiratory diseases and CVD refers to cardiovascular diseases.

2.2. Weather Data. Daily time series, weather data were obtained from the Hong Kong Observatory (HKO) from 1999 to 2009. The temperature metrics chosen were the following: daily maximum $\left(T_{\max }\right)$ and daily minimum $\left(T_{\min }\right)$ temperature, daily mean apparent temperature (AT), daily net effective temperature (NET), diurnal temperature range (DTR), and temperature change between neighbouring days (temp change) in terms of mean temperature $\left(T_{\text {mean }}\right), T_{\max }$ and $T_{\min } . T_{\max }$ and $T_{\min }$ were found on the HKO website database. $T_{\text {mean }}$ is defined as the average of today's minimum temperature $\left(T_{\min }\right)$ and the previous day's maximum temperature $\left(T_{\max }\right)$, as this approach is demonstrated to predict excess mortality [12]. In order to determine the effects of season on mortality, this paper examines summer and winter separately: $T_{\max }$ and max NET for summer, $T_{\min }$ and $\min$ NET for winter, as well as DTR in summer and winter. Summer is defined as June to August, whereas winter is defined as December to February. Box plots are produced to visualise the temperature-mortality relationships and identify temperature threshold for excess mortality.

$$
\text { DTR = daily maximum temperature - daily minimum temperature on the same day }
$$

Temp change $($ See $[19])=$ today's mean temperature - previous day's mean temperature.

The equation of Apparent Temperature incorporates wind speed and moisture characteristics to calculate the human perceived air temperature in terms of discomfort. It is calculated as follows $[16,17]$ :

$$
\mathrm{AT}=-2.653+\left(0.994 \times T_{a}\right)+\left(0.0153 \times T_{d}^{2}\right),
$$

where $T_{a}$ is air temperature and $T_{d}$ is dew point temperature.

Wind increases heat flow after mean daily temperatures are above $34^{\circ} \mathrm{C}$, wind-speed correction is not necessary when temperatures are below this [17]. The following is the equation for net effective temperature (NET):

$$
\begin{aligned}
\mathrm{NET}= & 37-\frac{37-T}{0.68-0.0014 \mathrm{R} \mathrm{H}+\left(1 / 1.76+1.4 v^{0.75}\right)} \\
& -0.29 T(1-0.01 \mathrm{RH}),
\end{aligned}
$$

where $T$ is the ambient temperature (in ${ }^{\circ} \mathrm{C}$ ), $v$ the wind speed (in $\mathrm{ms}^{-1}$ ), and $\mathrm{R} \mathrm{H}$ the relative humidity (in \%).

This study uses seasonal decomposition to remove short and long-term trends from the data, such as population ageing and seasonal highs or lows. The multiplicative seasonal decomposition model is as follows (deaths = trend-cycle $*$ seasonal factor $*$ anomaly) $[12,18]$ :

$$
\begin{gathered}
\mathrm{Xt}=\mathrm{TCt} * \mathrm{St} * \mathrm{It}, \\
T=1, \ldots, n,
\end{gathered}
$$

where TCt is the "trend-cycle" component, St is the "seasonal" component, and It is the "irregular" or "random" component.

\section{Results}

Table 3 outlines the weather parameters and mortality data distribution obtained from the study dataset.

3.1. Effects of Diurnal Temperature Range on Mortality. The diurnal temperature range (DTR) in Hong Kong is small (about $\left.2-5^{\circ} \mathrm{C}\right)$. The mean DTR is $4.19^{\circ} \mathrm{C}(\mathrm{SD}=1.436)$. Across the year, Figures 1, 2, and 4 demonstrate the DTR impact on all-cause mortality, CVD, and $\mathrm{RD}$, respectively, whereas Figures 3 and 5 illustrate the DTR impact on CVD in summer and $\mathrm{RD}$ in winter, respectively. Other DTRmortality relationships are summarised in Table 4 . 
TABLE 3: Summary statistics of daily death counts and weather parameters in 1999-2009.

\begin{tabular}{|c|c|c|c|c|}
\hline & Mean & SD & Minimum & Maximum \\
\hline \multicolumn{5}{|l|}{ Mortality categories } \\
\hline Daily total death (all-cause) & 91.11 & 14.36 & 39 & 162 \\
\hline Daily total death (respiratory) & 17.06 & 5.88 & 3 & 52 \\
\hline Daily total death (cardiovascular) & 21.61 & 5.98 & 3 & 54 \\
\hline \multicolumn{5}{|l|}{ Weather parameters } \\
\hline Daily mean temperature $\left({ }^{\circ} \mathrm{C}\right)$ & 23.21 & 5.09 & 8.2 & 31.8 \\
\hline Daily maximum temperature $\left({ }^{\circ} \mathrm{C}\right)$ & 25.57 & 5.31 & 9.3 & 35.4 \\
\hline Daily minimum temperature $\left({ }^{\circ} \mathrm{C}\right)$ & 21.35 & 5.14 & 5.8 & 29.4 \\
\hline Mean daily apparent temperature $\left({ }^{\circ} \mathrm{C}\right)$ & 26.43 & 8.01 & 6.2 & 39.7 \\
\hline Mean net effective temperature $\left({ }^{\circ} \mathrm{C}\right)$ & 16.25 & 7.19 & -6.6 & 27.5 \\
\hline Diurnal temperature range $\left({ }^{\circ} \mathrm{C}\right)$ & 4.22 & 1.46 & 0.7 & 12.2 \\
\hline Temperature change (mean temperature) between neighbouring days $\left({ }^{\circ} \mathrm{C}\right)$ & -0.001 & 1.31 & -5.9 & 4.9 \\
\hline
\end{tabular}

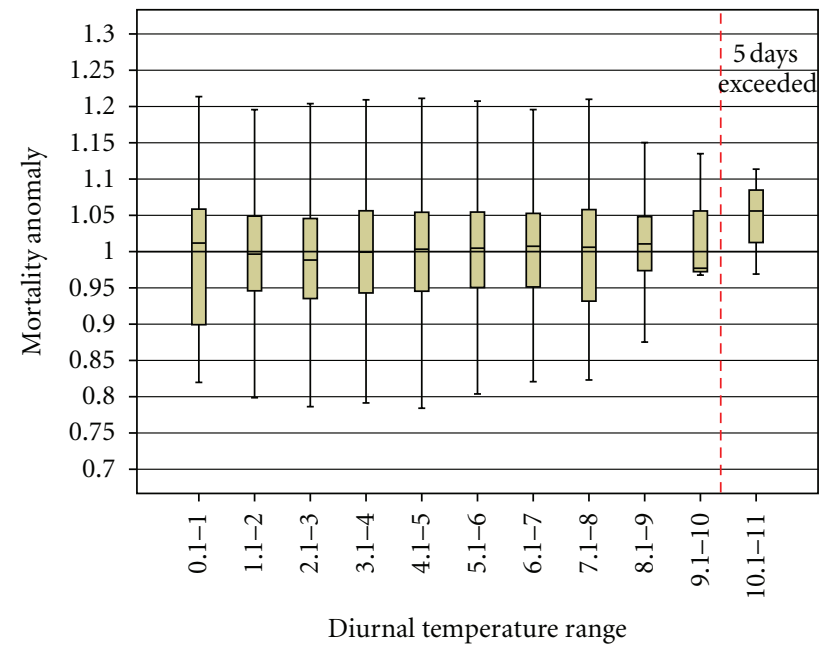

FIGURE 1: Detrended deseasoned mortality anomaly (all-cause) per $1^{\circ} \mathrm{C}$ temperature band for diurnal temperature range.

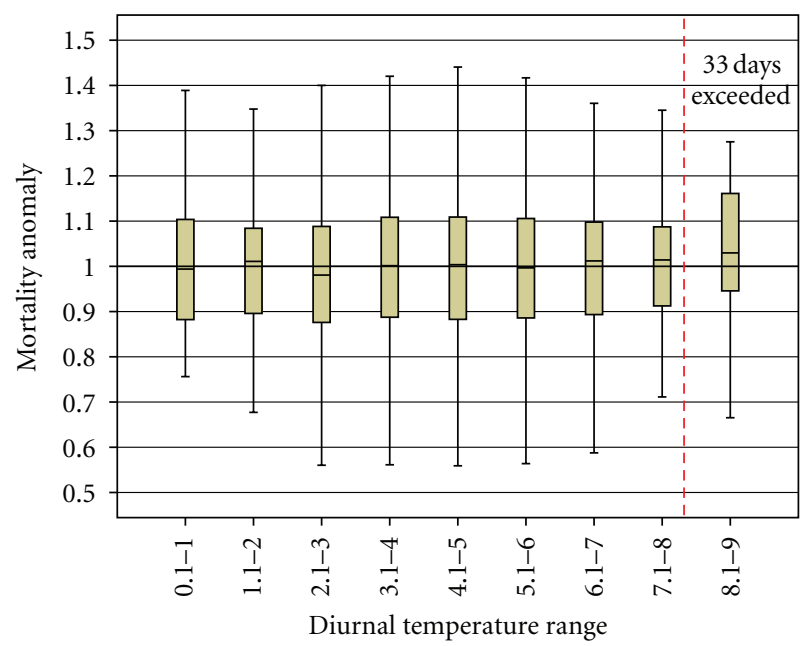

FIGURE 2: Detrended deseasoned mortality anomaly (CVD) per $1^{\circ} \mathrm{C}$ temperature band for diurnal temperature range. CVD refers to cardiovascular diseases.

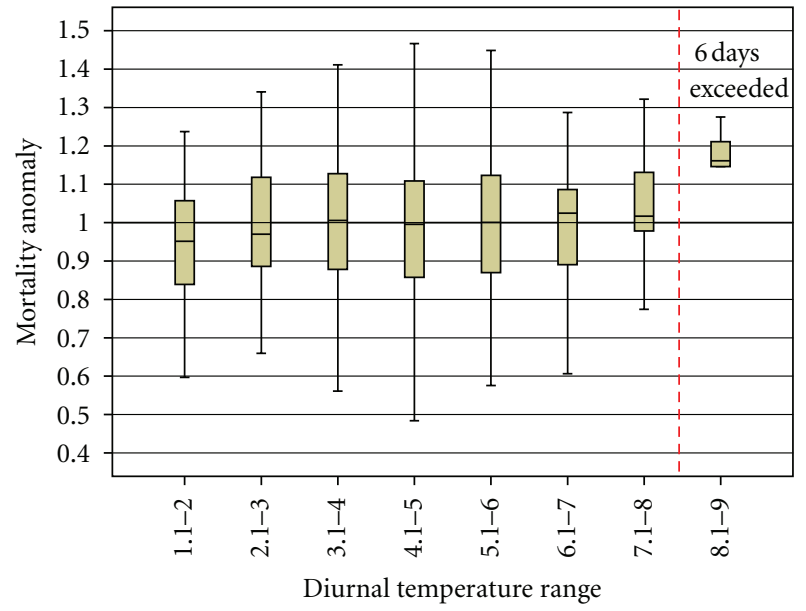

Figure 3: Detrended deseasoned mortality anomaly (CVD) per $1^{\circ} \mathrm{C}$ temperature band for diurnal temperature range in summer. Summer months are from June to August. CVD refers to cardiovascular diseases.

3.2. Effects of Temperature Change between Neighbouring Days on Mortality. Temperature change between neighbouring days is defined as today's mean temperature minus yesterday's mean temperature [19]. It is a different temperature measure from DTR. This study's mean temperature is defined as the average of yesterday's maximum temperature and today's minimum temperature [12]. The mean of temperature change $\left(T_{\text {mean }}\right)$ is $0(\mathrm{SD}=1.31)$, and for temperature change $\left(T_{\max }\right)$, the mean is $0(\mathrm{SD}=1.946)$. Figures 6 and 7 demonstrate that excess mortality (all-cause, RD) occurred when temperature change (mean temperature) exceeded $4.1^{\circ} \mathrm{C}$. Excess mortality (all-cause, $\mathrm{RD}$ ) also occurs when temperature change (maximum temperature) is greater than $5.6^{\circ} \mathrm{C}$ (see Figures 8 and 9). Apart from that, there appears to be some significant reduction below baseline mortality when temperature change is greater than $-4.0^{\circ} \mathrm{C}$. The changes vary from approximately $2-9 \%$ below baseline mortality (see 
TABLE 4: Summary of threshold temperatures for various temperature metrics.

\begin{tabular}{|c|c|c|c|}
\hline Temperature metrics & $\begin{array}{l}\text { Threshold temperature } \\
\left({ }^{\circ} \mathrm{C}\right)\end{array}$ & $\begin{array}{c}\text { No. of days exceeded from } \\
1999 \text { to } 2009\end{array}$ & $\begin{array}{c}\% \text { increase in median } \\
\text { mortality anomaly }\end{array}$ \\
\hline \multicolumn{4}{|l|}{$\overline{T_{\max } \text { (summer) }}$} \\
\hline All-cause & $\geq 35$ & 3 & 2.5 \\
\hline $\mathrm{RD}$ & Nil & Nil & Nil \\
\hline CVD & $\geq 35$ & 3 & 15 \\
\hline \multicolumn{4}{|l|}{$T_{\min }$ (winter) } \\
\hline All-cause & Nil & Nil & Nil \\
\hline $\mathrm{RD}$ & $\geq 21$ & 14 & 6 \\
\hline CVD & $\geq 21$ & 14 & 2.5 \\
\hline \multicolumn{4}{|l|}{ Mean AT } \\
\hline All-cause & $\leq 8$ & 10 & 2.5 \\
\hline $\mathrm{RD}$ & Nil & Nil & Nil \\
\hline CVD & $\leq 8(\geq 38)$ & $10(52)$ & $4(7)$ \\
\hline \multicolumn{4}{|l|}{ Mean NET } \\
\hline All-cause & $\geq 27$ & 4 & 2 \\
\hline $\mathrm{RD}$ & $\leq-3$ & 10 & 12 \\
\hline CVD & $\geq 27$ & 4 & 11 \\
\hline \multicolumn{4}{|l|}{ Max NET (summer) } \\
\hline All-cause & Nil & Nil & Nil \\
\hline $\mathrm{RD}$ & Nil & Nil & Nil \\
\hline CVD & $\geq 30$ & 38 & 4 \\
\hline Min NET (winter) & & Nil for all-cause, $\mathrm{RD}$, and $\mathrm{CV}$ & \\
\hline \multicolumn{4}{|l|}{ DTR (all season) } \\
\hline All-cause & $\geq 10$ & 5 & 6 \\
\hline $\mathrm{RD}$ & $\geq 8$ & 33 & 5 \\
\hline CVD & $\geq 8$ & 33 & 3 \\
\hline \multicolumn{4}{|l|}{ DTR (summer) } \\
\hline All-cause & $\geq 8$ & 6 & 4.5 \\
\hline $\mathrm{RD}$ & Nil & Nil & Nil \\
\hline CVD & $\geq 8$ & 6 & 16 \\
\hline \multicolumn{4}{|l|}{ DTR (winter) } \\
\hline All-cause & $\geq 7.1$ & 23 & 1.5 \\
\hline $\mathrm{RD}$ & $\geq 8$ & 6 & 15 \\
\hline CVD & $\geq 8$ & 6 & 2.5 \\
\hline \multicolumn{4}{|l|}{ Temp change $\left(T_{\text {mean }}\right)$} \\
\hline All-cause & $\geq 4.1$ & 11 & 6 \\
\hline $\mathrm{RD}$ & $\geq 4.1$ & 11 & 7 \\
\hline CVD & Nil & Nil & Nil \\
\hline \multicolumn{4}{|l|}{ Temp change $\left(T_{\max }\right)$} \\
\hline All-cause & $\geq 5.6$ & 7 & 3 \\
\hline $\mathrm{RD}$ & $\geq 5.6$ & 7 & 4 \\
\hline CVD & Nil & Nil & Nil \\
\hline Temp change $\left(T_{\min }\right)$ & & Nil for all-cause, $\mathrm{RD}$ and $\mathrm{CV}$ & \\
\hline
\end{tabular}




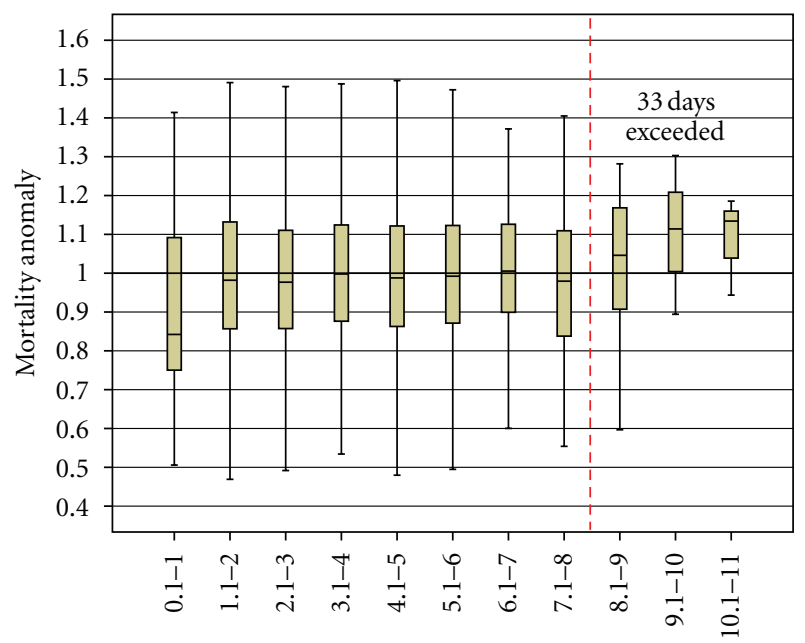

Diurnal temperature range

FIGURE 4: Detrended deseasoned mortality anomaly (RD) per $1^{\circ} \mathrm{C}$ temperature band for diurnal temperature range. $\mathrm{RD}$ refers to respiratory diseases.

Figures 6, 8, and 9). When the temperature cools off, the mortality rate drops.

Table 4 summarises temperature-mortality relationships across different temperature metrics. The table was produced based on the graphical relationship in the box plots produced in SPSS [20]. Threshold temperatures are identified when the median mortality anomaly increases above baseline (mortality anomaly $>1$ ). The number of days exceeding the thresholds refers to the number of days between 1999 and 2009. In short, mean NET, DTR, and temperature change between neighbouring days are demonstrated to be effective in predicting excess mortality.

\section{Discussion}

4.1. Temperature Metrics and Mortality in Hong Kong. Net effective temperature (NET) incorporates ambient temperature, wind speed, and relative humidity and is used in both hot and cold situations [14]. A high positive value indicates high heat load whereas a high negative value indicates substantial heat loss [14]. In order to establish a hot and cold weather warning system, the HKO uses the extreme values of NET as a gauge. It appears that the results support the current HKO's standard for issuing very hot weather warnings, with excess mortality occurring when daily maximum temperature exceeds $35^{\circ} \mathrm{C}$ (Table 4 ). There is no cold excess mortality during winter on lag day 0 (Table 4). However, excess mortality occurs when mean daily apparent temperature falls below $8^{\circ} \mathrm{C}$ (Table 4 ). Generally, excess mortality occurs in the upper and lower $2.5 \%$ of NET as indicated by $\mathrm{Li}$ and Chan [14]. It is interesting to note that there are many nil values when max NET and min NET are examined. This indicates that no excess mortality occurs using these two temperature metrics. Based on the above results, the current weather warning system in Hong Kong

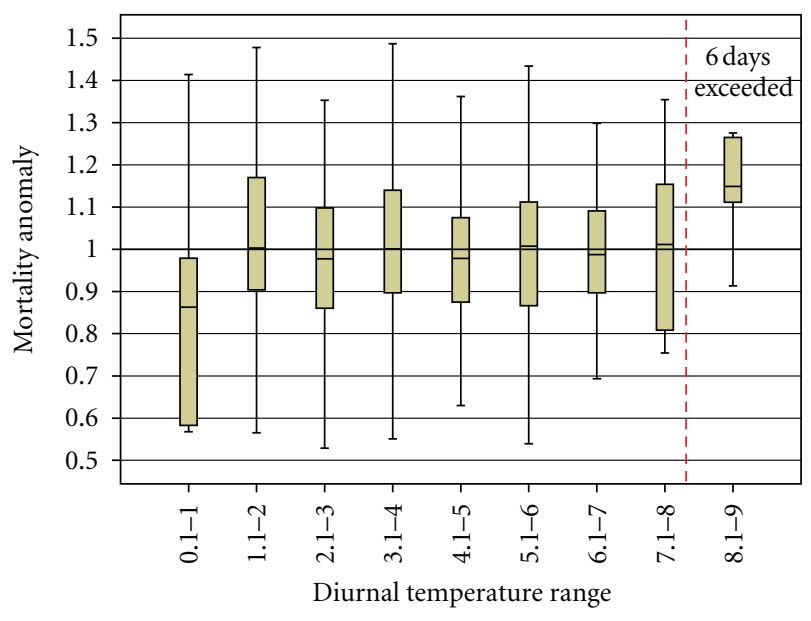

FIGURE 5: Detrended deseasoned mortality anomaly (RD) per $1^{\circ} \mathrm{C}$ temperature band for diurnal temperature range in winter. Winter months are from December to February. RD refers to respiratory diseases.

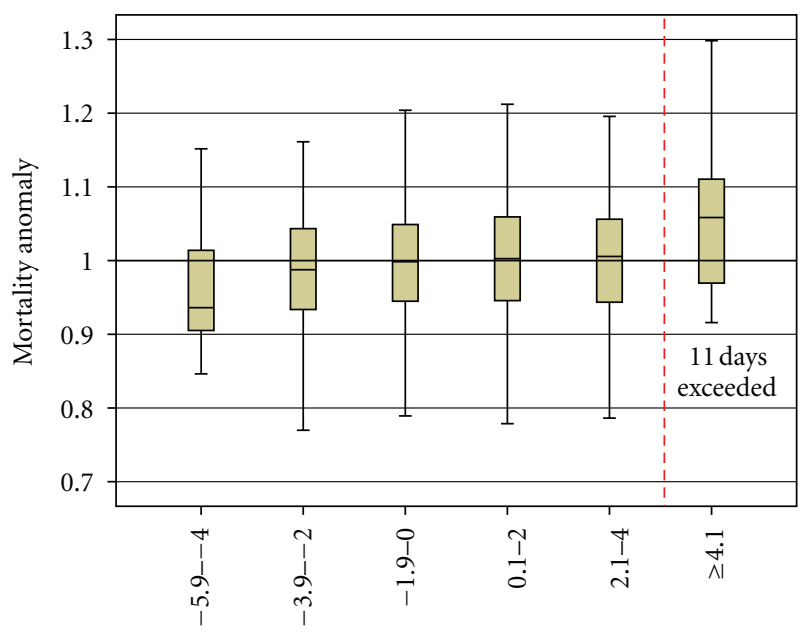

Temperature change (mean temperature) between neighbouring days

FIGURE 6: Detrended deseasoned mortality anomaly (all-cause) per $2^{\circ} \mathrm{C}$ temperature band for temperature change. Temperature change is defined as the differences between the mean temperature of neighbouring days.

might not accurately reflect people's experience in urban area for two reasons. First, the system depends on max NET and min NET to issue very hot and cold weather warning. Second, the warning system does not incorporate diurnal temperature range (DTR) and temperature change between neighbouring days.

A large DTR increases health risks (Figures 1, 2, 3, 4, and 5). There were 37 days from 1999 to 2009 with DTR exceeding $8^{\circ} \mathrm{C}$, associated with an increased median mortality ranging from 3-16\%. During summer (June to August), a large DTR indicates a very hot day (above 95th percentile) and warm night on the same day. For example, on 19th 


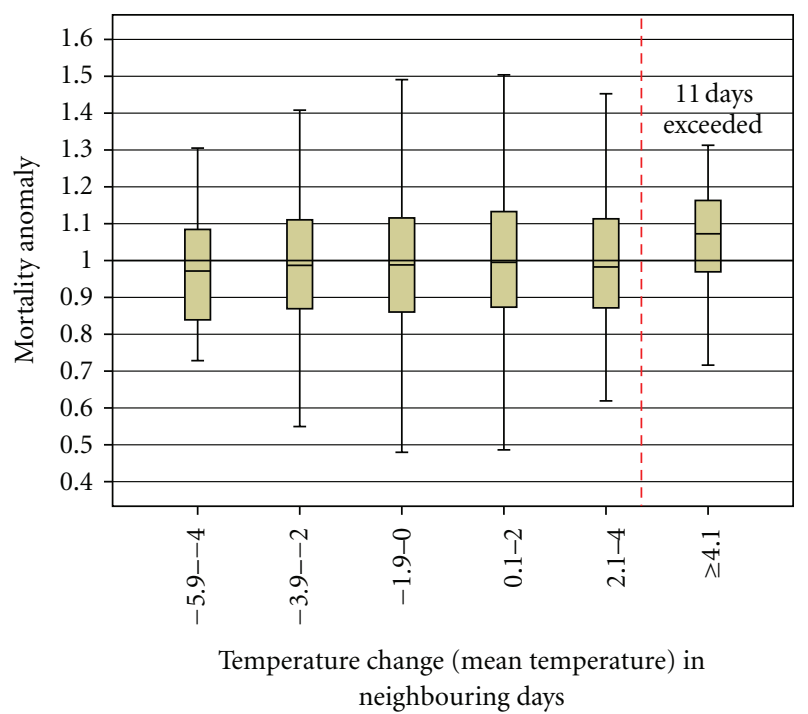

Figure 7: Detrended deseasoned mortality anomaly (RD) per $2^{\circ} \mathrm{C}$ temperature band for temperature change. Temperature change is defined as the differences between the mean temperature of neighbouring days. $\mathrm{RD}$ refers to respiratory diseases.

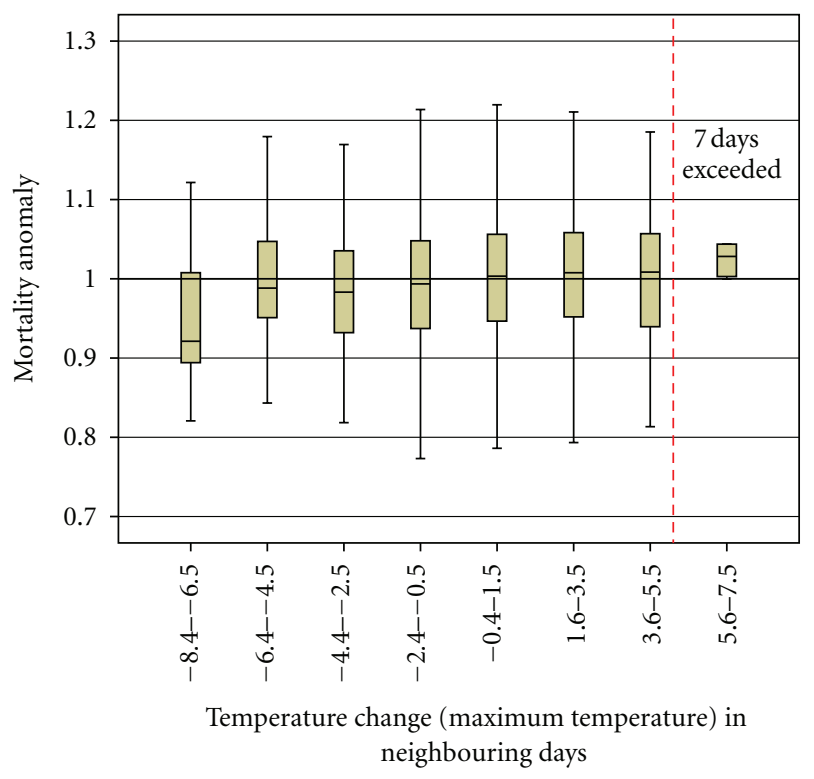

FIGURE 8: Detrended deseasoned mortality anomaly (all-cause) per $2^{\circ} \mathrm{C}$ temperature band for temperature change. Temperature change is defined as the differences between the maximum temperatures of neighbouring days.

July 2005 , the maximum temperature was $35.4^{\circ} \mathrm{C}$ and the minimum temperature was $26.9^{\circ} \mathrm{C}$. A lack of heat relief is associated with excess mortality because people do not have time to recover from heat exposure. This is important as hot nights are expected to increase in the future in Hong Kong [21].

The large DTR observed in Hong Kong is different from situations such as Melbourne when a large DTR indicates

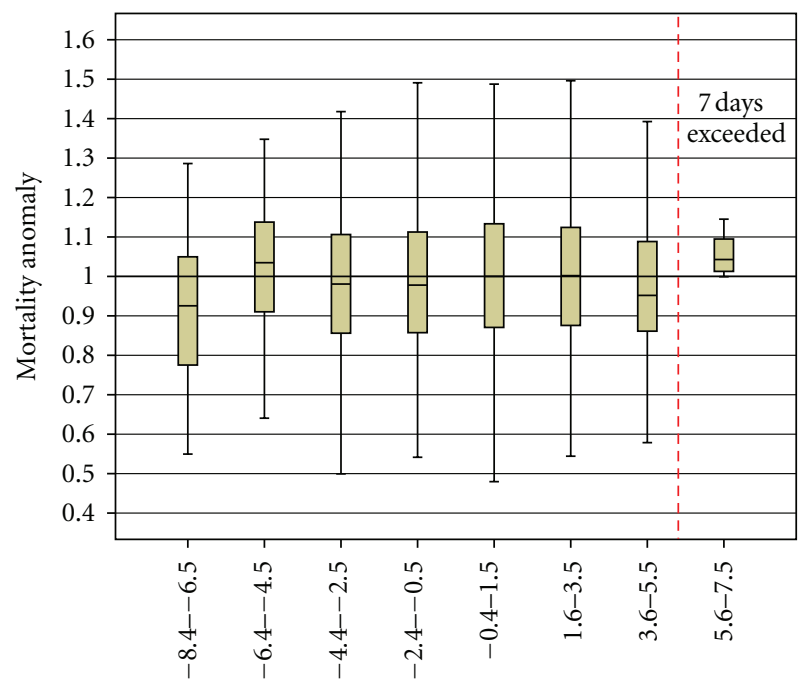

Temperature change (maximum temperature) in neighbouring days

Figure 9: Detrended deseasoned mortality anomaly (RD) per $2^{\circ} \mathrm{C}$ temperature band for temperature change. Temperature change is defined as the differences between the maximum temperatures of neighbouring days. $\mathrm{RD}$ refers to respiratory diseases.

a cool change in the afternoon; in other words, a hot day and cool night represent a large DTR [12]. During winter (December to February), a large DTR might indicate a cool day with unusually cold night in Hong Kong. For instance, on 26th December, 2002, the maximum temperature was $16^{\circ} \mathrm{C}$ and the minimum temperature was $7.2^{\circ} \mathrm{C}$. Exposure to such cold weather can trigger deaths caused by cardiovascular disease [22].

Temperature between neighbouring days is a temperature measure that is seldom investigated in the Hong Kong literature because rapid day-to-day temperature changes are perceived to be rare in Hong Kong [15]. A large temperature change indicates unstable weather systems and can increase the risk of mortality [19]. On the days with mean temperature change between neighbouring days greater than $4^{\circ} \mathrm{C}(13$ days from 1999 to 2009), excess mortality (all-cause and RD) increases by at least 7\% (see Figures 6 and 7). A large change in maximum temperature $\left(>5.5^{\circ} \mathrm{C}\right)$ occurred 8 times between 1999 and 2009, this results in about a 3 to $4 \%$ increase in excess mortality for all-cause and $\mathrm{RD}$, respectively (see Figures 8 and 9). In summary, the HKO should incorporate DTR and temperature change between neighbouring days in both hot and cold weather warnings. In refining the current warning system, it can prevent avoidable deaths and reduce the health risks of vulnerable populations.

4.2. Policy Implications. The HKO currently uses a fixed threshold temperature when issuing very hot and cold weather warnings. Sometimes excess mortality occurs before the warning is issued. Excess mortality occurs when DTR exceeds $8^{\circ} \mathrm{C}$ (Figures 1 and 2) and temperature change (mean temperature) of neighbouring days exceeds $4.1^{\circ} \mathrm{C}$ 
(Figure 5). Therefore, it is necessary to incorporate the above two temperature measures in a heat-health weather warning system. With temperature forecasts available for a week in advance, the government can issue advisories a few days ahead and then issue warnings as the threat increases. Our paper is one of the few that examine the impact of cold weather on mortality in Hong Kong. Understanding the cold threshold temperature will improve the current cold weather warning system. However, it is suggested that the elderly might have a lower heat threshold or a higher cold threshold for excess mortality [23]. It is because they have impaired thermoregulation, and the use of drugs can also affect normal homeostasis. In future research, a cohort study design with focus groups and questionnaires can help to target the more vulnerable elderly population.

There are several limitations of this study. The findings of this study might not necessarily be generalized to cities from temperate regions or even other subtropical regions, due to the varying demography and socioeconomic factors. Additionally, an ecological study design is susceptible to ecological fallacy, so it is not able to explain individuallevel responses from aggregate data. It is acknowledged that air pollution is an important confounder, but it was not included in the study due to the scope of this project. In terms of mortality data quality, there might be misclassification of diseases. Furthermore, air temperature fails to consider indoor temperature which is influenced by the housing design and the use of air conditioning and heating. It is beyond the scope of the current study design to analyse the differences in exposure based on the time spent either indoors or outdoors. Finally, preliminary findings of lag day 1-3 do not reveal any significant excess mortality. However, with longer lag days excess mortality might result.

\section{Conclusions}

This study aimed to determine the impact of extreme temperature on mortality in Hong Kong. It identified various temperature thresholds for excess mortality. Specifically, mean net effective temperature (NET), diurnal temperature range (DTR), and temperature change (mean temperature) are shown to be effective temperature metrics in predicting excess mortality in Hong Kong. To the best of our knowledge, temperature change between neighbouring days is a temperature metric that has not been studied in Hong Kong before. The Hong Kong Observatory should consider incorporating DTR and temperature change in the heat-health weather warning system, rather than using a fixed weather stress index that is only based on NET. This study demonstrates that the current heat threshold for very hot weather warnings (daily maximum temperature $\geq 33^{\circ} \mathrm{C}$ ) predict excess summer mortality in Hong Kong. In comparison, the threshold for very cold weather warning (daily minimum temperature $\leq 12^{\circ} \mathrm{C}$ ) does not appear to predict excess cold mortality on the same day as exposure. Moreover, winter mortality is higher than summer mortality but is seldom studied in Hong Kong. A greater emphasis on cold-related mortality research can refine the cold weather warning systems in Hong Kong and reduce winter mortality.

\section{Conflict of Interests}

The authors declare no potential conflict of interests with respect to the research, authorship, and/or publication of this paper.

\section{Disclosure}

This research received no specific grant from any funding agency in the public, commercial, or not-for-profit sectors.

\section{Acknowledgments}

The authors would like to thank the Census and Statistics Department of Hong Kong for providing the death microdata set and the Hong Kong Observatory for providing the weather data.

\section{References}

[1] Y. Y. Yan, "Association between daily mortality and weather in Hong Kong," The Internet Journal of Public Health, vol. 1, no. 2, 2011.

[2] Y. Y. Yan, "Seasonal variations of mortality in Hong Kong," Biological Rhythm Research, vol. 40, no. 5, pp. 425-431, 2009.

[3] Y. Y. Yan, "The influence of weather on human mortality in Hong Kong," Social Science and Medicine, vol. 50, no. 3, pp. 419-427, 2000.

[4] Y. K. Leung, K. M. Yip, and K. H. Yeung, "Relationship between thermal index and mortality in Hong Kong," Meteorological Applications, vol. 15, no. 3, pp. 399-409, 2008.

[5] E. Y. Y. Chan, W. B. Goggins, J. J. Kim, and S. M. Griffiths, "A study of intracity variation of temperature-related mortality and socioeconomic status among the Chinese population in Hong Kong," Journal of Epidemiology and Community Health, vol. 66, no. 4, pp. 322-327, 2012.

[6] J. Y. Chung, Y. Honda, Y. C. Hong, X. C. Pan, Y. L. Guo, and H. Kim, "Ambient temperature and mortality: an international study in four capital cities of East Asia," Science of the Total Environment, vol. 408, no. 2, pp. 390-396, 2009.

[7] H. D. Kan, J. Jia, and B. H. Chen, "Temperature and daily mortality in Shanghai: a time-series study," Biomedical and Environmental Sciences, vol. 16, no. 2, pp. 133-139, 2003.

[8] H. Kim, J. S. Ha, and J. Park, "High temperature, heat index, and mortality in 6 major cities in South Korea," Archives of Environmental and Occupational Health, vol. 61, no. 6, pp. 265-270, 2006.

[9] H. Kan, S. J. London, H. Chen et al., "Diurnal temperature range and daily mortality in Shanghai, China," Environmental Research, vol. 103, no. 3, pp. 424-431, 2007.

[10] W. W. S. Tam, T. W. Wong, S. Y. Chair, and A. H. S. Wong, "Diurnal temperature range and daily cardiovascular mortalities among the elderly in Hong Kong," Archives of Environmental and Occupational Health, vol. 64, no. 3, pp. 202-206, 2009. 
[11] Y. K. Leung, K. H. Yeung, E. W. L. Ginn, and W. M. Leung, "Climate change in Hong Kong," Technical Note 107, Hong Kong Observatory, Kowloon, Hong Kong, 2004.

[12] N. Nicholls, C. Skinner, M. Loughnan, and N. Tapper, "A simple heat alert system for Melbourne, Australia," International Journal of Biometeorology, vol. 52, no. 5, pp. 375-384, 2008.

[13] G. Chen, Y. Zhang, G. Song et al., "Is diurnal temperature range a risk factor for acute stroke death?" International Journal of Cardiology, vol. 116, no. 3, pp. 408-409, 2007.

[14] P. W. Li and S. T. Chan, "Application of a weather stress index for alerting the public to stressful weather in Hong Kong," Meteorological Applications, vol. 7, no. 4, pp. 369-375, 2000.

[15] W. Xu, Effects of apparent temperature on mortality in a cohort of older population in Hong Kong [MPhil Thesis], The University of Hong Kong, Pokfulam, Hong Kong, 2011.

[16] R. G. Steadman, “The assessment of sultriness. Part II: effects of wind, extra radiation and barometric pressure on apparent temperature," Journal of Applied Meteorology, vol. 18, no. 7, pp. 874-885, 1979.

[17] L. S. Kalkstein and K. M. Valimont, "An evaluation of summer discomfort in the United States using a relative climatological index," Bulletin of the American Meteorological Society, vol. 67, no. 7, pp. 842-848, 1986.

[18] M. E. Loughnan, N. Nicholls, and N. J. Tapper, "The effects of summer temperature, age and socioeconomic circumstance on acute myocardial infarction admissions in Melbourne, Australia," International Journal of Health Geographics, vol. 9, article 41, 2010.

[19] Y. Guo, A. G. Barnett, W. Yu et al., "A large change in temperature between neighbouring days increases the risk of mortality," PLoS ONE, vol. 6, no. 2, Article ID e16511, 2011.

[20] SPSS, ,Version 19 Statistical Package For Social Science, SPSS, Chicago, Ill, USA, 2011.

[21] T. C. Lee, K. Y. Chan, and W. L. Ginn, "Projection of extreme temperatures in Hong Kong in the 21st century," Acta Meteorologica Sinica, vol. 25, no. 1, pp. 1-20, 2011.

[22] G. C. Donaldson and W. R. Keatinge, "Early increases in ischaemic heart disease mortality dissociated from and later changes associated with respiratory mortality after cold weather in South East England," Journal of Epidemiology and Community Health, vol. 51, no. 6, pp. 643-648, 1997.

[23] P. H. Chau, K. C. Chan, and J. Woo, "Hot weather warning might help to reduce elderly mortality in Hong Kong," International Journal of Biometeorology, vol. 53, no. 5, pp. 461-468, 2009. 

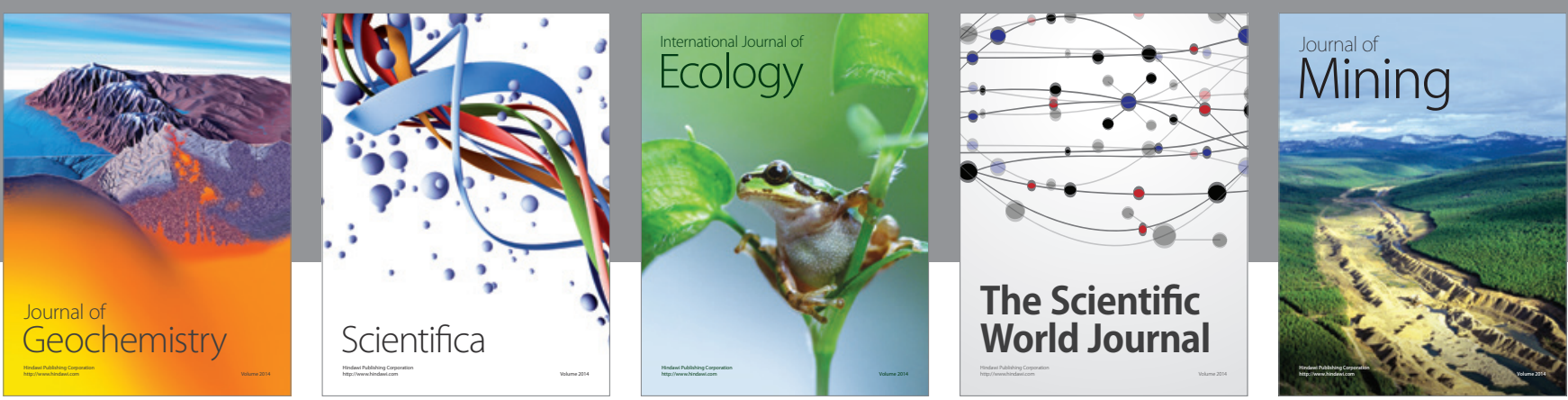

The Scientific World Journal
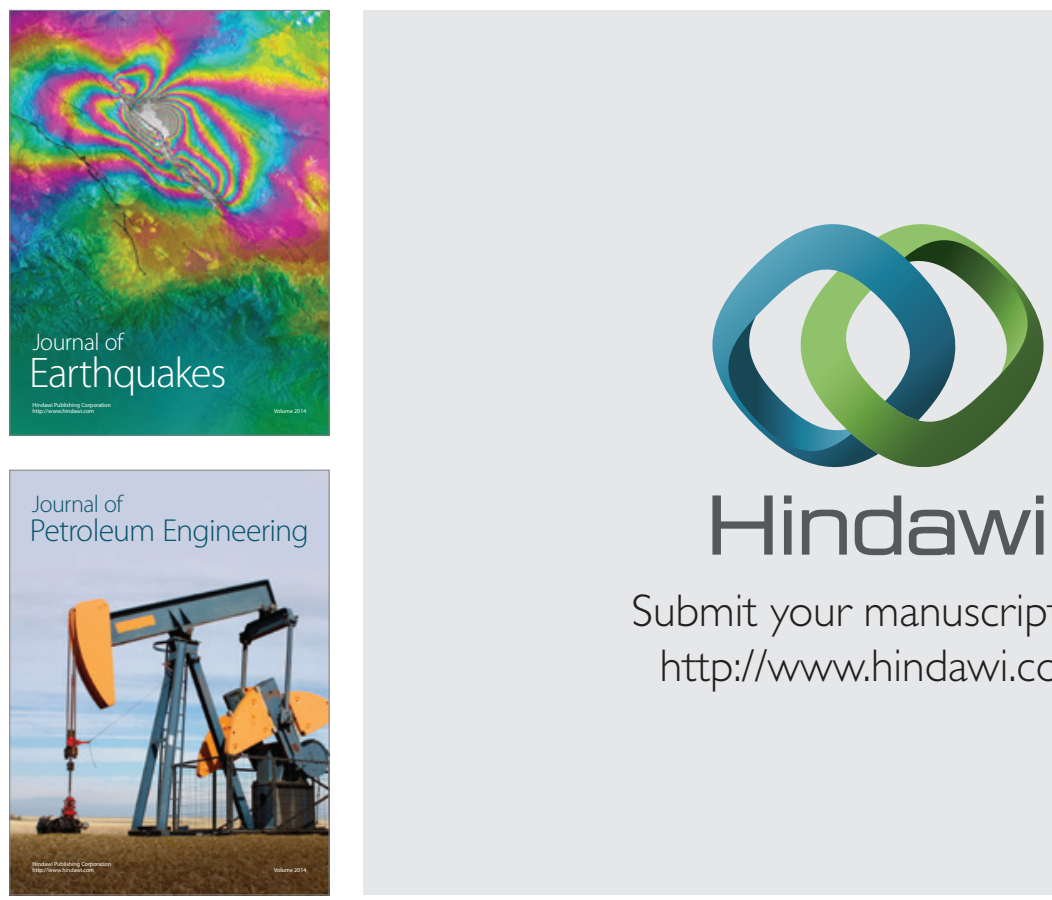

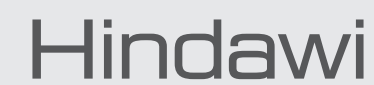

Submit your manuscripts at

http://www.hindawi.com
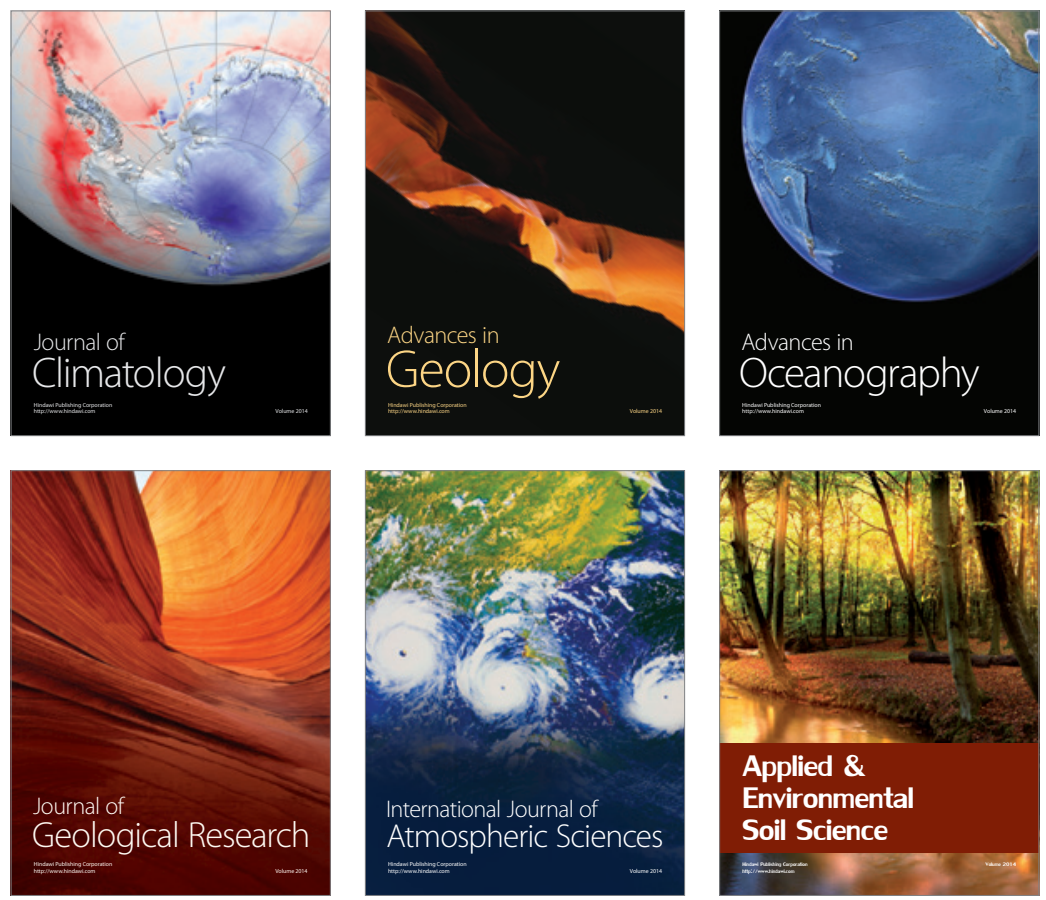
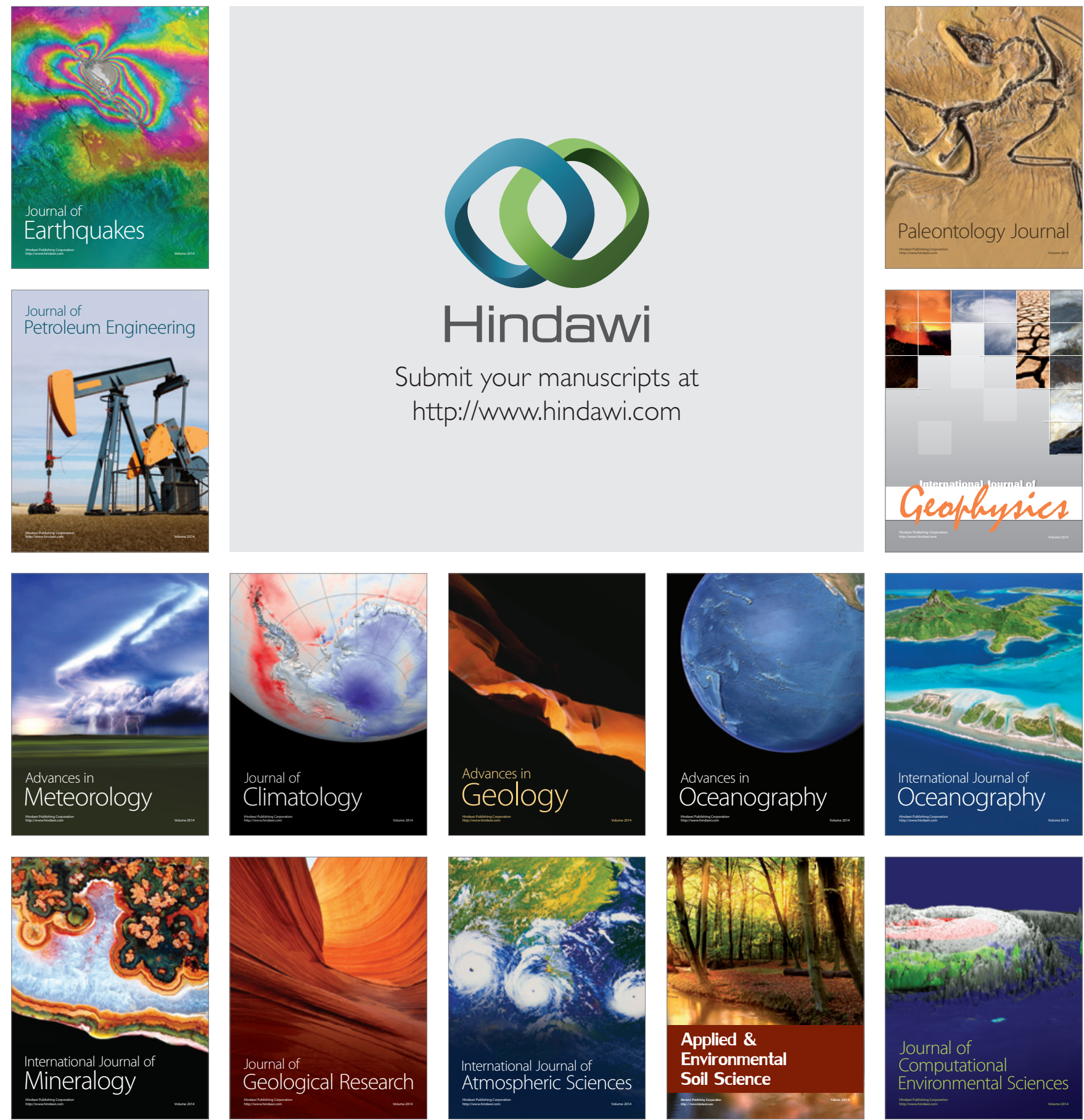